\title{
Article
}

\section{Analysis of the Causes of Cerebral Palsy in Kazakhstan}

\author{
Saule Issenova ${ }^{1}$, Nagima Mamedalieva ${ }^{1}$, Gani Bodykov ${ }^{1}$, Ayat Assemov ${ }^{2, *}$, and Balzira Bizhekova ${ }^{1}$ \\ 1 Asfendiyarov Kazakh National Medical University; isienova10@mail.ru ; mamedalieva kz@mail.ru ; $\underline{\text { ffin- }}$ \\ ish3@gmail.com; b balzira@mail.ru ; \\ 2 Al-Farabi Kazakh National University; ayat.asemov@gmail.com \\ * Correspondence: ayat.asemov@gmail.com ; Tel.: +77072053310
}

Abstract: Introduction: Cerebral palsy is the most common childhood disability

Aims: Analyze and determine the main risk factors for the development of cerebral palsy in the population of Kazakhstan

Materials and methods: Retrospective, analytical "case" - "control". Core group "case" - medical records of 100 pregnant women whose children at different ages has been diagnosed with cerebral palsy

Results: Thus, a retrospective analysis revealed the following features and complications in the perinatal period, which could promote the formation of cerebral palsy in children. Analytical results of the study are set significant results in cerebral palsy development

Conclusion: Premature birth and urinary tract infections turned out to be the largest contributors to the development of cerebral palsy, however, according to statistics, the rate of preterm birth, as well as the detection of infections, stably remains at the same level, while the number of cerebral palsy has been steadily growing since the early 1990s in Kazakhstan.

Keywords: cerebral palsy; perinatal risks; children; pregnancy; childbirth;

\section{Introduction}

Cerebral palsy $(\mathrm{CP})$ is the most common childhood disability. [1-3] Over the past decade, important discoveries have been made in the field of early diagnosis, prevention and treatment, which have influenced the incidence, prognosis and effectiveness of treatment.

$\mathrm{CP}$ is the most common physical disability in childhood, but cerebral palsy is not a purely childhood cause of disability, as most people with cerebral palsy survive into adulthood.[4]

CPis a general term for a clinically and ethologically heterogeneous group of persistent, but not unchanged, movement and / or posture disorders. Epilepsy, as well as cognitive, sensory and behavioral disorders, often accompany this movement disorder.[5,6]

The etiology of CPis diverse [7-13], but there are a number of well-known prenatal / perinatal risk factors, including premature birth, multiple births, infection, intrauterine growth restriction, indicators of compromise during labor, neonatal encephalopathy, and congenital anomalies. $[6,7,14]$

Premature babies account for $43 \%$ of all cases of cerebral palsy.[1,2,15]

Maternal infections can lead to cerebral palsy by transmitting pathogens to the fetus (even without a detectable maternal inflammatory response [16] and induction of persistent systemic inflammation, which can increase the sensitivity of the brain to subsequent exposures. $[17,18]$ 
Infections such as toxoplasmosis, rubella, cytomegalovirus and herpes simplex virus during pregnancy have been associated with an increased risk of cerebral palsy[3,19,20], but these agents account for only a small proportion of CP cases in SVD. Objectives of this work to analyze and determine the main risk factors for the development of cerebral palsy in the population of Kazakhstan

\section{Materials and Methods}

Retrospective, analytical "case" - "control". Core group "case" - medical records of 100 pregnant women whose children at different ages has been diagnosed with cerebral palsy, a control group of 200 pregnant women - respectively, the diagnosis of cerebral palsy in children is excluded.

There was conducted retrospective analysis of 300 histories of genera, the history of neonatal development, metabolic women cards drawn from Almaty maternity homes in the period from 2003 to 2019. The diagnosis of cerebral palsy was established in age from 3 months to 10 years.

We studied the clinical and medical history, laboratory data, peculiarities of pregnancy and childbirth, newborn condition at birth.

Results of the analysis of medical records of women and children used for analytical study, in the setting of maternity homes/offices and perinatal centers

\section{Results}

This section may be divided by subheadings. It should provide a concise and precise description of the experimental results, their interpretation, as well as the experimental conclusions that can be drawn.

\subsection{Kazakhstan}

Statistical data disability in any country is one of the most important medical and social health indicators, while reflecting the level of socio-economic development of society, environmental conditions and the quality of preventive measures.

Despite the relatively low incidence $(81.4$ per 100,000$)$ of cerebral palsy in Kazakhstan compared to developed countries [6,21-23], the country has seen an increase in cases over the past 30 years (Figure 1), although in other countries, on the contrary, there has been a decrease.[2] 


\section{Frequency of cerebral palsy per 100 thousand children}

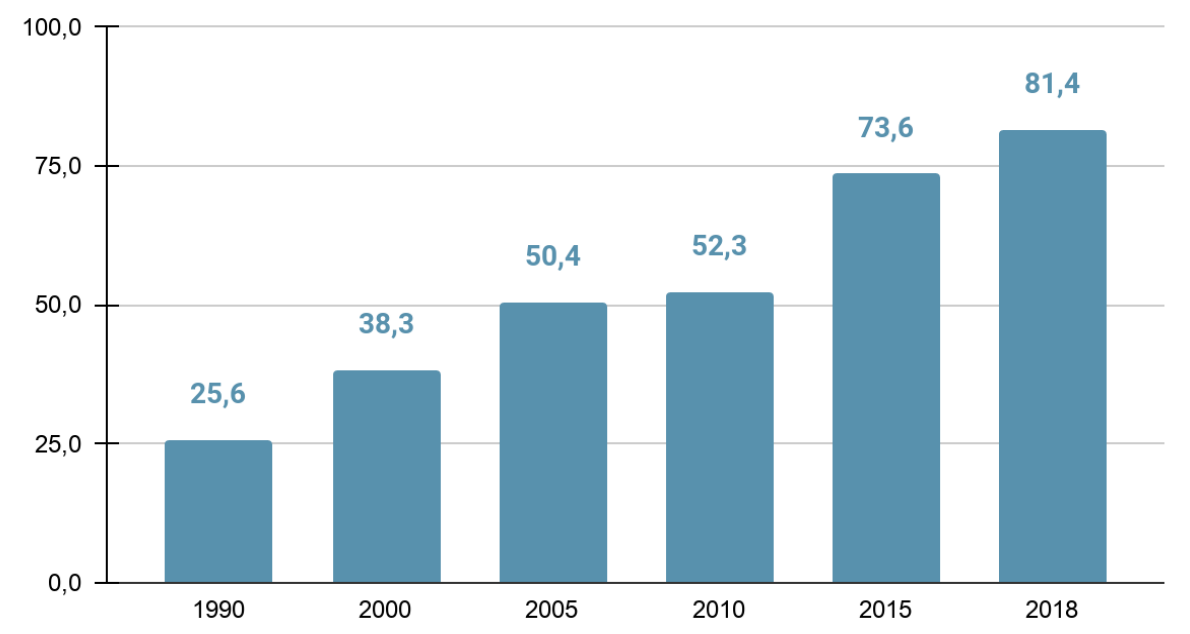

Figure 1. The dynamics of the frequency of cerebral palsy per 100 thousand children under 18 years old, Kazakhstan, 1990-2018.

\subsection{Analysis results}

The average age of the patients of the main group was $26.6 \pm 1.9$ years in control group $24.8 \pm 1.7$ years, significant differences were not detected. Thus, in the study and control group of genera occurred in patients of reproductive age.

It is known that the concomitant extragenital diseases are unfavorable backdrop to the course of pregnancy and childbirth, as well as state of intrauterine fetus and newborn. From extragenital diseases frequency kidney and urinary tract diseases were significantly more $(p<0.001)$ were observed in patients of the main group $(36,4 \pm 1,7) \%$, whereas in the control group this index was $17,0 \pm 2,1 \%$.

One of the factors that affect the course of pregnancy and childbirth is a gynecological disease. From the analysis it follows that gynecological diseases significantly $(\mathrm{P}<0.001)$ more frequently detected in patients of the main group. Thus, chronic inflammation of the uterus, cervical erosion is more than 3 times more frequent in patients of the main group $(19 \pm 2,1 \%$ and $6.0 \pm 2.7 \%$, respectively) compared with the control. It draws attention to the high frequency of abortions in patients of the main group $27 \%$, compared with women in the control group of $8 \%$.

Characteristics of menstrual function showed that the average age of menarche at pregnant women and control group had no significant difference and amounted to $13.4 \pm 1.5$ years and $12.8 \pm 1.4$ years.

It is known that the initial state of the reproductive system has a significant impact on the course and outcome of pregnancy. Significant differences in the frequency of spontaneous pregnancy in women Interrupt the main group. Since spontaneous abortions, developing pregnancy, fetal death, ectopic pregnancy were significantly more frequent in patients of the main group $(18 \%$ and $1.5 \%$, respectively, $\mathrm{P}<0.001)$. Thus, every fifth patient, who gave birth to a child with cerebral palsy, was at high risk for the development of perinatal complications.

Revealed a high frequency of chronic infections, such as the kidney and urinary tract, chronic inflammatory diseases of uterus and cervix erosion in patients of the main group 
indicates an important role in the genesis of infection complications of gestation and perinatal lesions formation in the fetus.

Currently, among the causes of miscarriage infectious agents are leaders. Mostly this mixed infection and, in rare cases, a mono-infection. The greatest danger is the persistent infection, are asymptomatic when infection "nests" deep in the crypts of endometrial and intracellularly and is difficult to diagnose, which manifests itself mainly in the occurrence of pregnancy. Infection is transmitted primarily by the upward and hematogenic and transplacental. Activators can be varied:. Viruses, bacteria, streptococci and staphylococci, Klebsiella, Proteus, Mycoplasma, etc. The infection may lead to lesions of nondeveloping pregnancy (NP) with fetus and fetus formations (placenta membranes, umbilical cord, water), and without infection. NP Risk of infectious origin is particularly high in the presence of endogenous inflammatory lesions in the mother, genital and extragenital localization. The role of latent infection in women, especially in disorders of the immune relationship between mother and fetus. The infection can lead to the NP in the short terms, as well as to the formation of the CDF and other perinatal damage to the fetus.

Study of peculiarities of birth showed that the study group was significantly $(21 \%$ and $5 \%$ ) were more births were completed by cesarean section, while in $90.4 \%$ of cases of cesarean section performed on an emergency basis. The main indications for caesarean sections were abruptio placentae (33\%), fetal threatening condition (19\%), preeclampsia severe (19\%), eclampsia (4.7\%), at FFTS twins (4.7\%) and also combines indications for operative delivery - primapara older and large fetus.

Obstetric aids and manipulation such as labor induction, birth-stimulation, episiotomy, vacuum extraction fetal applied only in $4 \%$ of patients of the main group.

Analyzing the features of a current delivery, it should be noted that the most frequent complication in patients of the main group were untimely amniorrhea $63 \pm 2,1 \%$ vs. 24,5 $\pm 1,1 \%(\mathrm{p}<0.001)$ cases in the control group.

Underlines high incidence of preterm birth in the primary study group $(51 \%$ and $2 \%$, respectively, $\mathrm{P}<0.001$ ). These findings are consistent with the majority of domestic and foreign authors, which by one of the predisposing factors to the development of cerebral palsy include preterm labor. Prematurity has a large proportion of patients with a history of cerebral palsy and is, according to different authors, from 19 to $33.2 \%$, while among all infants this figure is $4-8 \%$. It is found that cerebral paralysis develops in premature infants, $8.7 \%$, and its frequency is reduced in proportion to increase of gestational age and body mass. Cerebral palsy risk factors for the development of premature infants is associated with hypoxic injury,

Qualification newborn status was based on inspection, Apgar scores, trends analysis early neonatal period of adaptation. Evaluation of the newborn Apgar estimated at 7-10 points recorded significantly more frequently in the control group. mild asphyxia significantly more often observed in children of the main group $(18 \%$ and $2 \%, \mathrm{P}<0.001)$. Heavy asphyxia at birth observed only among newborns main group (6\%), whereas among the control group childbirth - absent.

Held on birthweight infants distribution analysis. Children weighing up to 1000 grams were $4 \%$, from 1000 to $2000 \mathrm{~g}-30 \%$ by 2000 and up to $3000 \mathrm{~g}$ in $36.4 \%$ were born in the main group, while children weighing 3000.0 and above were significantly more marked in the control group $(\mathrm{P}<0,05)$. The following Table 1 shows some data of the statistical analysis of the results. 
Table 1. The main risk factors for cerebral palsy in the perinatal period, Almaty, 2019. $(\mathrm{P}<0.001)$

\begin{tabular}{|l|l|l|l|l|}
\hline & $\begin{array}{c}\text { Odds } \\
\text { Ratio }\end{array}$ & $\begin{array}{c}\text { 95\% Confidence } \\
\text { Limits }\end{array}$ & $\begin{array}{l}\text { Case } \\
\text { percentage }\end{array}$ & Control \\
\hline Age & 3,45 & $1,95-6,11$ & $36 \%$ & $32 \%$ \\
\hline Preterm birth & 14,41 & $4,13-50,26$ & $18 \%$ & $1,5 \%$ \\
\hline Abortion in anamnesis & 4,25 & $2,16-8,35$ & $27 \%$ & $8 \%$ \\
\hline Pyelonephritis during pregnancy & 2.75 & $1.58-4.76$ & $36 \%$ & $17 \%$ \\
\hline Cervical erosion & 2.68 & $1.71-7.92$ & $19 \%$ & $6 \%$ \\
\hline Miscarriage & 14.41 & $4,13-50,26$ & $18 \%$ & $1.5 \%$ \\
\hline $\begin{array}{l}\text { Premature and prenatal rupture of } \\
\text { membranes }\end{array}$ & 5.24 & $3,12-8,81$ & $63 \%$ & $24,5 \%$ \\
\hline
\end{tabular}

\subsection{Findings}

Thus, according to a retrospective analysis revealed the following features and complications in the perinatal period, which could promote the formation of cerebral palsy in children. Analytical results of the study are set fairly significant results in cerebral palsy development:

- $\quad$ high frequency of urinary tract infections during the period of gestation were significantly more $(\mathrm{P}<0.001)$ is found in patients of the main group $(36 \%)$, while this figure was $5.0 \pm 2.1 \%$ in the control group;

- $\quad$ gynecological diseases significantly $(\mathrm{P}<0.001)$ were more common in patients of the main group. Thus, chronic inflammation of the uterus and cervix erosion is more than 3 times encountered in patients of the main group (19\%);

- $\quad$ in the study history in patients of the main group was significantly $(\mathrm{P}<0.001)$ were observed more frequently prematurity (51\%) and miscarriage $(18 \%)$;

- $\quad$ increase in the frequency of emergency caesarean sections (90\%);

- the most frequent complication in patients of the main group were delayed and prenatal amniorrhea 63\%;

- high frequency (48\%) children at birth asphyxia varying severity. Asphyxia mild $24 \%$, moderate severity $18 \%$ and $6 \%$ severe.

The results of a retrospective study showed a significant role of adverse Pregravidal background, complications of pregnancy and childbirth in the implementation of the ICP.

From this perspective, the problem of children born with cerebral palsy is relevant, there are many unresolved issues of both scientific and practical planning that require continued multilateral and in-depth research.

\section{Discussion}

Various sources report that premature children make a significant contribution to the number of children diagnosed with cerebral palsy (from 35 to 43\%). [1,2,24]

There is conflicting evidence from numerous studies: large analyzes of preterm births in some countries (mostly with high income) indicate that preterm birth rates have been increasing since the early 2000s. Blencowe et al.[25] reported that of 65 countries with reliable data on preterm births, 62 countries experienced an increase between 2000 and 2010. [26-28] At the same time, the rate of preterm births increased in most countries, but the magnitude of this increase was different. The increase in the multiple birth rate, 
as well as the frequency of preterm births with multiple pregnancies, contributed to an increase in the overall preterm birth rate.[29]

In a series of works by Joshua P Vogel et al. (Switzerland, Thailand), which analyze the epidemiology of preterm birth, (from 22 weeks to 37 weeks) there are data reports that the growth of preterm birth is declining in developed countries.[30]

In about half of the European countries (out of 19 included in the study), no changes occurred or the number of preterm births in single pregnancies decreased due to the development of preventive and diagnostic measures. [31]

In Kazakhstan, the rate of preterm birth remains at the level of $6.4 \%$ [32-34] according to official data and reports of domestic authors, and according to the WHO it is 8.8 cases per 100 births.[35]

Urinary tract infections, which are also one of the causes of cerebral palsy, also remain at the same level $[33,34,36]$, they are also often the cause of premature birth, which in combination can give an increased risk of developing cerebral palsy in the fetus / child [2628], especially noted pyelonephritis[29], which in our work reliably showed a connection in the development of cerebral palsy.

One of the limitations of this work was that we did not divide children by weight, since the previous authors had already specified that among newborns with a weight below $1500 \mathrm{~g}$. there is a decrease in the total number of cerebral palsy. [15,22,23]

The same stable indicators are observed for all other categories that can cause the development of cerebral palsy [37], which raises additional questions regarding the increase in the incidence of cerebral palsy in Kazakhstan.

The limitation was the lack of a single database and scattered information across all maternity hospitals in Almaty, and the lack of an electronic database, which made it difficult to collect material for work. Further work is required to clarify the main reason for the growth of cerebral palsy in Kazakhstan and find ways to prevent them.

Author Contributions: Conceptualization, S.I. and N.M.; methodology, G.B.; software, A.A.; validation, S.I., B.N. and N.M.; formal analysis, A.A.; investigation, G.B.; data curation, N.M.; writingoriginal draft preparation, A.A.; writing - review and editing, A.A.; supervision, S.I.; project administration, B.N.. All authors have read and agreed to the published version of the manuscript.

Funding: This research received no external funding

Institutional Review Board Statement: Not applicable.

Informed Consent Statement: Not applicable

Data Availability Statement: The data that support the findings of this study are available on request from the corresponding author. The data are not publicly available due to privacy or ethical restrictions

Acknowledgments: Not applicable.

Conflicts of Interest: The authors declare no conflict of interest

\section{References}

1. Novak I, Morgan C, Adde L, Blackman J, Boyd RN, Brunstrom-Hernandez J, et al. Early, Accurate Diagnosis and Early Intervention in Cerebral Palsy. JAMA Pediatrics 2017;171. https://doi.org/10.1001/jamapediatrics.2017.1689.

2. Novak I, Morgan C, Fahey M, Finch-Edmondson M, Galea C, Hines A, et al. State of the Evidence Traffic Lights 2019: Systematic Review of Interventions for Preventing and Treating Children with Cerebral Palsy. Current Neurology and Neuroscience Reports 2020;20. https://doi.org/10.1007/s11910-020-1022-z. 
3. Smithers-Sheedy H, McIntyre S, Gibson C, Meehan E, Scott H, Goldsmith S, et al. A special supplement: findings from the Australian Cerebral Palsy Register, birth years 1993 to 2006. Developmental Medicine \& Child Neurology 2016;58. https://doi.org/10.1111/dmcn.13026.

4. Himmelmann K, Sundh V. Survival with cerebral palsy over five decades in western Sweden. Developmental Medicine \& Child Neurology 2015;57. https://doi.org/10.1111/dmcn.12718.

5. Peter L Rosenbaum, N. Paneth, A. Leviton, M. Goldstein. The definition and classification of cerebral palsy. Developmental Medicine \& Child Neurology 2007;49:1-44.

6. Blair E, Watson L. Epidemiology of cerebral palsy. Seminars in Fetal and Neonatal Medicine 2006;11. https://doi.org/10.1016/j.siny.2005.10.010.

7. Blair EM, Nelson KB. Fetal growth restriction and risk of cerebral palsy in singletons born after at least 35 weeks' gestation. American Journal of Obstetrics and Gynecology 2015;212. https://doi.org/10.1016/j.ajog.2014.10.1103.

8. Streja E, Miller JE, Bech BH, Greene N, Pedersen LH, Yeargin-Allsopp M, et al. Congenital cerebral palsy and prenatal exposure to self-reported maternal infections, fever, or smoking. American Journal of Obstetrics and Gynecology 2013;209. https://doi.org/10.1016/j.ajog.2013.06.023.

9. Graham HK, Rosenbaum P, Paneth N, Dan B, Lin J-P, Damiano DL, et al. Cerebral palsy. Nature Reviews Disease Primers 2016;2. https://doi.org/10.1038/nrdp.2015.82.

10. Topp M, Huusom LD, Langhoff-Roos J, Delhumeau C, Hutton JL, Dolk H. Multiple birth and cerebral palsy in Europe: a multicenter study. Acta Obstetricia et Gynecologica Scandinavica 2004;83. https://doi.org/10.1111/j.0001-6349.2004.00545.x.

11. Meeraus WH, Petersen I, Gilbert R. Association between Antibiotic Prescribing in Pregnancy and Cerebral Palsy or Epilepsy in Children Born at Term: A Cohort Study Using The Health Improvement Network. PLOS ONE $2015 ; 10$. https://doi.org/10.1371/journal.pone.0122034.

12. Wu YW, Colford JJM. Chorioamnionitis as a Risk Factor for Cerebral Palsy. JAMA $2000 ; 284$. https://doi.org/10.1001/jama.284.11.1417.

13. Wu YW. Chorioamnionitis and Cerebral Palsy in Term and Near-Term Infants. JAMA $2003 ; 290$. https://doi.org/10.1001/jama.290.20.2677.

14. MCINTYRE S, TAITZ D, KEOGH J, GOLDSMITH S, BADAWI N, BLAIR E. A systematic review of risk factors for cerebral palsy in children born at term in developed countries. Developmental Medicine \& Child Neurology 2013;55. https://doi.org/10.1111/dmcn.12017.

15. Platt MJ, Cans C, Johnson A, Surman G, Topp M, Torrioli MG, et al. Trends in cerebral palsy among infants of very low birthweight (\&lt;1500 g) or born prematurely (\&lt;32 weeks) in 16 European centres: a database study. The Lancet 2007;369. https://doi.org/10.1016/S0140-6736(07)60030-0.

16. Leviton A, Allred EN, Kuban KCK, Hecht JL, Onderdonk AB, O'Shea TM, et al. Microbiologic and Histologic Characteristics of the Extremely Preterm Infant's Placenta Predict White Matter Damage and Later Cerebral Palsy. The ELGAN Study. Pediatric Research 2010;67. https://doi.org/10.1203/PDR.0b013e3181bf5fab.

17. Dammann O. Edited by Alan Leviton Persistent neuro-inflammation in cerebral palsy: a therapeutic window of opportunity? Acta Paediatrica 2007;96. https://doi.org/10.1111/j.1651-2227.2007.00097.x.

18. Dammann O. Causality, mosaics, and the health sciences. Theoretical Medicine and Bioethics $2016 ; 37$. https://doi.org/10.1007/s11017-016-9360-1.

19. Smithers-Sheedy H, Raynes-Greenow C, Badawi N, McIntyre S, Jones CA. Congenital cytomegalovirus is associated with severe forms of cerebral palsy and female sex in a retrospective population-based study. Developmental Medicine \& Child Neurology 2014;56. https://doi.org/10.1111/dmcn.12467.

20. Smithers-Sheedy H, Raynes-Greenow C, Badawi N, Fernandez MA, Kesson A, McIntyre S, et al. Congenital Cytomegalovirus among Children with Cerebral Palsy. The Journal of Pediatrics 2017;181. https://doi.org/10.1016/j.jpeds.2016.10.024.

21. Maenner MJ, Benedict RE, Arneson CL, Yeargin-Allsopp M, Wingate MS, Kirby RS, et al. Children With Cerebral Palsy. Epidemiology 2012;23. https://doi.org/10.1097/EDE.0b013e31823a4205.

22. Sellier E, Surman G, Himmelmann K, Andersen G, Colver A, Krägeloh-Mann I, et al. Trends in prevalence of cerebral palsy in children born with a birthweight of 2,500 g or over in Europe from 1980 to 1998. European Journal of Epidemiology 2010;25. https://doi.org/10.1007/s10654-010-9474-0.

23. Colver A, Fairhurst C, Pharoah POD. Cerebral palsy. The Lancet 2014;383. https://doi.org/10.1016/S0140-6736(13)61835-8.

24. Fahey MC, Maclennan AH, Kretzschmar D, Gecz J, Kruer MC. The genetic basis of cerebral palsy. Developmental Medicine \& Child Neurology 2017;59. https://doi.org/10.1111/dmcn.13363.

25. Blencowe H, Cousens S, Oestergaard MZ, Chou D, Moller A-B, Narwal R, et al. National, regional, and worldwide estimates of preterm birth rates in the year 2010 with time trends since 1990 for selected countries: a systematic analysis and implications. The Lancet 2012;379. https://doi.org/10.1016/S0140-6736(12)60820-4.

26. Frey HA, Klebanoff MA. The epidemiology, etiology, and costs of preterm birth. Seminars in Fetal and Neonatal Medicine 2016;21. https://doi.org/10.1016/j.siny.2015.12.011.

27. Goldenberg RL, Culhane JF, Iams JD, Romero R. Epidemiology and causes of preterm birth. The Lancet $2008 ; 371$. https://doi.org/10.1016/S0140-6736(08)60074-4.

28. Beck S, Wojdyla D, Say L, Pilar Bertran A, Meraldi M, Harris Requejo J, et al. The worldwide incidence of preterm birth: a systematic review of maternal mortality and morbidity. Bulletin of the World Health Organization 2010;88. https://doi.org/10.2471/BLT.08.062554. 
29. Cunnington M, Kortsalioudaki C, Heath P. Genitourinary pathogens and preterm birth. Current Opinion in Infectious Diseases 2013;26. https://doi.org/10.1097/QCO.0b013e328360dc31.

30. Vogel JP, Chawanpaiboon S, Moller A-B, Watananirun K, Bonet M, Lumbiganon P. The global epidemiology of preterm birth. Best Practice \& Research Clinical Obstetrics \& Gynaecology 2018;52. https://doi.org/10.1016/j.bpobgyn.2018.04.003.

31. Zeitlin J, Szamotulska K, Drewniak N, Mohangoo A, Chalmers J, Sakkeus L, et al. Preterm birth time trends in Europe: a study of 19 countries. BJOG: An International Journal of Obstetrics \& Gynaecology 2013;120. https://doi.org/10.1111/14710528.12281.

32. Marat A, Ukybassova T. Structure and factors of the risk of premature birth. Journal of Clinical Medicine of Kazakhstan 2017;3. https://doi.org/10.23950/1812-2892-JCMK-00501.

33. Republican Center for Healthcare Development. Statistical compilations "Health of the population of the Republic of Kazakhstan and the activities of health care organizations" (Russ./Kaz.) n.d. http://rcrz.kz/index.php/ru/?option=com_content\&view=article\&id=973 (accessed April 2, 2021).

34. KAZSTAT. Agency for Strategic planning and reforms of the Republic of Kazakhstan. Bureau of National statistics n.d. https://stat.gov.kz (accessed March 31, 2021).

35. Chawanpaiboon S, Vogel JP, Moller A-B, Lumbiganon P, Petzold M, Hogan D, et al. Global, regional, and national estimates of levels of preterm birth in 2014: a systematic review and modelling analysis. The Lancet Global Health $2019 ; 7$. https://doi.org/10.1016/S2214-109X(18)30451-0.

36. Mamedaliyeva NM, Kurmanova AM, Lokshin VN, Kurmanova GM, Sh. Issenova S. Clinical and immunological parallels in pregnancy loss. Gynecological Endocrinology 2017;33. https://doi.org/10.1080/09513590.2017.1404238.

37. Agency for Strategic planning and reforms of the Republic of Kazakhstan. Bureau of National statistics n.d. https://stat.gov.kz. 